Absorption of Foreign Protein by Anafhylactic Lungs. 129 tinctly resistant. The blood prevents the reaction if mixed with anaphylactic blood.

( $f$ ) Humoral anaphylaxis and humoral immunity. This third seeming paradox is illustrated by the blood of partially immunized rabbits, which contains a thermo-labile anaphylactic substance, partially inhibited by a thermo-stable antitoxin.

\title{
77 (1255)
}

Absorption of foreign protein by the anaphylactic lungs.

By W. H. Manwarimg and Harold E. Crowe.

[From the Department of Bacteriology and Experimental Pathology, Leland Stanford Jr. University.]

If the lungs of an anaphylactic guinea pig are repeatedly perfused with dilute foreign protein, either in Locke's solution or in 50 per cent. normal blood, the lungs are thrown into a typical anaphylactic response.

Quantitative titrations of the perfusion fluid, by means of a specific precipitating serum, show no recognizable changes in the amount of protein as a result of the repeated passages through the lungs.

The titrations therefore furnish no support, either for the sessile receptor hypothesis of Ehrlich, or for the protein-destruction theory of Vaughan. 